\title{
Editorial
}

\section{Special Issue for Asian Congress on Gas Turbines 2020 (ACGT2020)}

(C) Science Press, Institute of Engineering Thermophysics, CAS and Springer-Verlag GmbH Germany, part of Springer Nature 2022

The special issue of Journal of Thermal Science (JTS) is dedicated to the Asian Congress on Gas Turbines 2020 (ACGT2020). ACGT is an international conference on advanced technologies of gas turbine, which was established in 2005 and held in turn by the Gas Turbine Society of Janpan (GTSJ), Korean Society for Fluid Machinery (KSFM), Chinese Society of Engineering Thermophysics (CSET), and India Institute of Technoloty Bomby (IIT Bombay) every two years. ACGT has been committed to providing an excellent communication platform for scholars and engineers in the field of gas turbines.

Due to the COVID-19 pandemic, ACGT2020 was postponed and successfully held from August 18th to 19th, 2021, in Qingdao, Shandong Province, China. It was organized by the Chinese Society of Engineering Thermophysics, Gas Turbine Society of Japan, Korean Fluid Machinery Association, and Indian Institute of Technology Bombay, and co-sponsored by the Institute of Engineering Thermophysics, Shanghai Advanced Research Institute, Qingdao Institute of Aeronautical Technology and Qingdao Science and Technology Bureau.

The chairman of the ACGT2020 Organizing Committee is Prof. ZHU Junqiang, the director of the Institute of Engineering Thermophysics. The conference was hosted by Prof. HUANG Weiguang, the vice president of Shanghai Advanced Research Institute. Over the current decade, considerable efforts have been devoted to the development of the gas turbine aiming at higher efficiency, lower emission and more fuel-flexible operation. The adoption of lighter weight engine structures, a larger size of components and high-pressure ratio cycles enable the modern gas turbine to reach unprecedented performance. Under the theme of "Gas Turbine and Energy Conversion System", this conference serves as an international forum on gas turbine technology to bring together scientists and engineers in this field to exchange ideas. Participants presented the latest developments in the field of gas turbine technology in Asia and the world, disseminated the most advanced research outputs, and discussed the future direction of the gas turbine technology.

A total of four invited keynote speeches were presented on ACGT2020. The first keynote speech titled "Key Technologies and Applications of Light-duty Aero-engine" was delivered by Prof. ZHU Junqiang. The second keynote speech, "The role of gas turbine in Korea's energy transition" was presented by Mr. LEE Kwangyol from Doosan Heavy Industries \& Construction, Korea. Prof. CHAKRAVARTHY Satya from Aerospace Engineering Department, Institute of Technology Madras, India gave a talk on "Recent Progress in Gas Turbine Combustion Technologies" thereafter. Mr. FUKUIZUMI Yasushi from Mitsubishi Heavy Industries in Japan gave the last keynote speech titled "Pathway to achieve Carbon Neutrality-What is the role for Gas Turbine?" Besides, one special report, "Considerations for scientific journal development and Introduction to $J T S$ " was given by Prof. ZHANG Na, who is the Executive Chief Editor of Journal of Thermal Science and Journal of Engineering Thermophysics.

A total of 11 technical sessions were hosted on ACGT2020, including Aerodynamic Design \& Optimization, Combustor \& Combustions, Modeling \& Controls, Structures \& Dynamics, Cooling Technology, Turbine Aerodynamics, Unsteady Flows, Compressor Aerodynamics, Heat Transfer, Materials \& Coatings and Unsteady Flows. There are 75 papers submitted from Japan, Korea, New Zealand and China; more than 100 participants registered and attended the conference either on-line or on-site. They mainly come from the University of Tokyo, Hokkaido University of Science, Seoul National University, Institute of Engineering 
Thermophysics, CAS, Shanghai Advanced Research Institute, CAS, AECC Shenyang Engine Institute, Aerospace Technology Institute, China Aerodynamics Research and Development Center, Tsinghua University, Beihang University of Aeronautics and Astronautics, Nanjing University of Aeronautics and Astronautics, Northwestern Polytechnical University, Shanghai Jiaotong University, Xi' an Jiaotong University, North China Electric Power University, MHI, IHI Corporation, Shanghai Electric Power Generation Group, Shanghai Electric Gas Turbine Co., Ltd., Dongfang Electric.

This special issue of the Journal of Thermal Science (JTS) includes 25 excellent articles which represent the state-of-the-art technologies of gas turbines. The scope of this special issue covers a wide range of engineering and scientific topics on gas turbines, such as compressor aerodynamics, advanced combustion technology and cooling film in turbines. As the organizing committee member of ACGT2020, we are very grateful for the privilege of organizing a special issue to publish these outstanding works. We believe it is the best way to express our gratitude to all the researchers for their contribution to the development of gas turbine technology as well as for their firm support to ACGT2020. At last, we also would like to thank all the session chairs, reviewers and authors for their great efforts to accomplish this special issue.

The Special Issue Editors

Professor ZHU Junqiang Institute of Engineering Thermophysics, Chinese Academy of Sciences, China

Professor HUANG Weiguang Shanghai Advanced Research Institute, Chinese Academy of Sciences, China

Professor ZHANG Hongwu

Institute of Engineering Thermophysics, Chinese Academy of Sciences, China

Professor DU Juan

Institute of Engineering Thermophysics, Chinese Academy of Sciences, China 